Polymer Journal, Vol. 9, No. 6, pp 653-655 (1977)

SHORT COMMUNICATION

\title{
Preparation of Well-Defined Polymers by Polymer-Coupling Reaction. I. A Facile Evaluation of the Extent of Polymer-Coupling Reaction
}

\author{
Mikio Takaki and Ryuzo Asami \\ Department of Synthetic Chemistry, Nagoya Institute of Technology, \\ Gokiso-cho, Showa-ku, Nagoya 466, Japan.
}

(Received April 27, 1977)

\begin{abstract}
KEY WORDS Polymer-Coupling Reaction / Extent of Coupling / Living Polymer / Number-Average Molecular Weight / Number of Polymer Molecules /
\end{abstract}

Many studies have recently reported on the syntheses of block and graft copolymers by the coupling reaction between two prepolymers. ${ }^{1}$ We also have been studying the polymer-coupling reaction by means of either addition ${ }^{2 \mathrm{a}}$ or substitution. ${ }^{2 b}$ In particular, by using a living polymer as one of the prepolymers, we intend to prepare well-defined polymers of the sort shown herein. In these studies of the polymercoupling reactions, it is desirable to determine the extent of the reaction accurately and easily. In this paper, a method is proposed for direct evaluation of the extent of coupling reaction.

If the number-average molecular weight, $\left(\bar{M}_{n}\right)_{\mathrm{R}}$, of a polymer mixture recovered from any coupling reaction system of A-polymer and B-polymer is measured, the number of polymer molecules, $N_{\mathrm{R}}$, in the system can be expressed by the equation

$$
N_{\mathrm{R}}=\frac{\left[\left(\bar{M}_{n}\right)_{\mathrm{A}} N_{\mathrm{A}}+\left(\bar{M}_{n}\right)_{\mathrm{B}} N_{\mathrm{B}}\right]}{\left(\bar{M}_{n}\right)_{\mathrm{R}}}
$$

where $\left(\bar{M}_{n}\right)_{\mathbf{A}}$ and $\left(\bar{M}_{n}\right)_{\mathrm{B}}$ are the number-average molecular weights, and $N_{\mathrm{A}}$ and $N_{\mathrm{B}}$ are the initial number of molecules of A-polymer and B-polymer in the system, respectively. $N_{\mathrm{R}}$ can be related to the number of A-polymer molecules which have coupled with B-polymer, $n_{A}$, in a simple relation as shown in Table I. Therefore, the extent of coupling of A-polymer, $n_{\mathrm{A}} / N_{\mathrm{A}}$, can be calculated by the equation

$$
\frac{n_{\mathrm{A}}}{N_{\mathrm{A}}}=\left\{\frac{1+\nu-\left[\left(\bar{M}_{n}\right)_{\mathrm{A}}+\left(\bar{M}_{n}\right)_{\mathrm{B}} \nu\right]}{\left(\bar{M}_{n}\right)_{\mathrm{R}}}\right\} f
$$

where $\nu$ stands for $N_{\mathrm{B}} / N_{\mathrm{A}}$, and $f$ is equal to unity in the case of monofunctional A-polymer, but for bifunctional A-polymer $f$ is given in Table II. In the equations, $N_{\mathrm{A}}, N_{\mathrm{B}}$, or $n_{\mathrm{A}}$ may be expressed in moles.

In the proposed method, the recovered polymer mixture needs no further fractionation or separation for the evaluation of the extent of coupling, but its number-average molecular weight should be measured accurately. It is not necessary to consider the kind of solvent for the extraction of products, the contamination of products by uncoupled precursor molecules, the distribution of precursor molecules on coupler molecules, etc. However, the extent of any side reaction should be evaluated in advance, if it may change the number of polymer molecules for the scission of the main chains or coupling of the prepolymers of the same kinds during the desired coupling reaction.

Prior to the application of this method to a polymer-coupling reaction, it was tested by a blend of two inert polymers which was chosen as an extreme example having no coupling reaction in the system, where the values of $n_{\mathrm{A}} / N_{\mathrm{A}}$ were found equal to zero within experimental error, as shown in Table III.

This method will be suitable for study of the coupling reaction in detail, especially for the 


\section{TAKAKI and R. AsAMI}

Table I. Type of resultant polymers and the number of polymer molecules in the system after the coupling reaction between A-polymer and B-polymer

\begin{tabular}{|c|c|c|c|c|c|c|}
\hline \multirow{2}{*}{ No. } & \multirow{2}{*}{\multicolumn{2}{|c|}{$\begin{array}{l}\text { Type of resultant } \\
\text { coupled polymer }\end{array}$}} & \multicolumn{2}{|c|}{ Nature of reactant } & \multirow{2}{*}{$\begin{array}{l}\text { No. of molecules of A- } \\
\text { polymer that coupled } \\
\text { with B-polymer }\end{array}$} & \multirow{2}{*}{$\begin{array}{l}\text { No. of polymer mole- } \\
\text { cules, } N_{\mathrm{R}} \text {, in the system } \\
\text { after the reaction }\end{array}$} \\
\hline & & & A-polymer & B-polymer & & \\
\hline \multirow[t]{2}{*}{1} & Block & $\begin{array}{l}\mathrm{AB} \\
\mathrm{ABA}\end{array}$ & $\begin{array}{l}\text { Monofunca } \\
\text { Monofunc }\end{array}$ & $\left.\begin{array}{l}\text { Monofunc } \\
\text { Bifunc }^{c}\end{array}\right\}$ & $n_{\mathrm{A}}$ & $N_{\mathrm{A}}+N_{\mathrm{B}}-n_{\mathrm{A}}^{\mathrm{b}}$ \\
\hline & & $\begin{array}{l}\mathrm{BAB} \\
\mathrm{ABAB} \ldots \mathrm{d}\end{array}$ & $\begin{array}{l}\text { Bifunc } \\
\text { Bifunc }\end{array}$ & $\left.\begin{array}{l}\text { Monofunc } \\
\text { Bifunc }\end{array}\right\}$ & $n_{\mathrm{A}}\left\{\begin{array}{l}n_{\mathrm{A}}\left(\chi_{\mathrm{b}}\right)_{\mathrm{A}} \\
n_{\mathrm{A}}\left[1-\left(\chi_{\mathrm{b}}\right)_{\mathrm{A}}\right]\end{array}\right\}^{\circ}$ & $N_{\mathrm{A}}+N_{\mathrm{B}}-n_{\mathrm{A}}\left[1+\left(\chi_{\mathrm{b}}\right)_{\mathrm{A}}\right]$ \\
\hline 2 & Ring-shaped & $(-\mathrm{AB}-)_{n} \mathrm{f}$ & Bifunc & Bifunc & $n_{\mathrm{A}}$ & $N_{\mathrm{A}}+N_{\mathrm{B}}-n_{\mathrm{A}}(2-1 / \bar{n})^{\mathrm{g}}$ \\
\hline 3 & Graft & $\mathbf{A}_{n} \mathbf{B}$ & Monofunc & Multifunc ${ }^{\mathrm{h}}$ & & (2) \\
\hline 4 & Star-shaped & $\mathrm{A}_{n} \mathrm{~B}$ & Monofunc & Multifunci $^{i}$ & $n_{\mathrm{A}}$ & \\
\hline 5 & Cross-linked & $\mathbf{A}_{n} \mathbf{B}_{n}$ & Bifunc & Multifunc & $n_{\mathrm{A}}\left\{\begin{array}{l}n_{\mathrm{A}}\left(\chi_{\text {inter }}\right)_{\mathrm{A}} \\
n_{\mathrm{A}}\left[1-\left(\chi_{\text {inter }}\right)_{\mathrm{A}}\right]\end{array}\right\}^{\mathrm{j}}$ & $N_{\mathrm{A}}+N_{\mathrm{B}}-n_{\mathrm{A}}\left[1+\left(\chi_{\text {inter }}\right)_{\mathrm{A}}\right]$ \\
\hline
\end{tabular}

a Monofunctional.

b $N_{\mathrm{A}}$, total number of A-polymer molecules; $N_{\mathrm{B}}$, total number of B-polymer molecules.

c Bifunctional.

d Obtained when no backbiting reaction takes place.

- $\left(\chi_{b}\right)_{A}$, fraction of number of A-polymer molecules coupled bifunctionally.

f Obtained when all molecules react bifunctionally.

g $\bar{n}$, average number of $\mathrm{AB}$ sequence in ring polymers.

h Multifunctional and linear.

i Multifunctional low-molecular-weight compound.

$j\left(\chi_{\text {inter }}\right)_{\mathrm{A}}$, fraction of number of A-polymer molecules coupled intermolecularly.

Table II. Type of resultant polymers and factors $(f)$ of eq 2

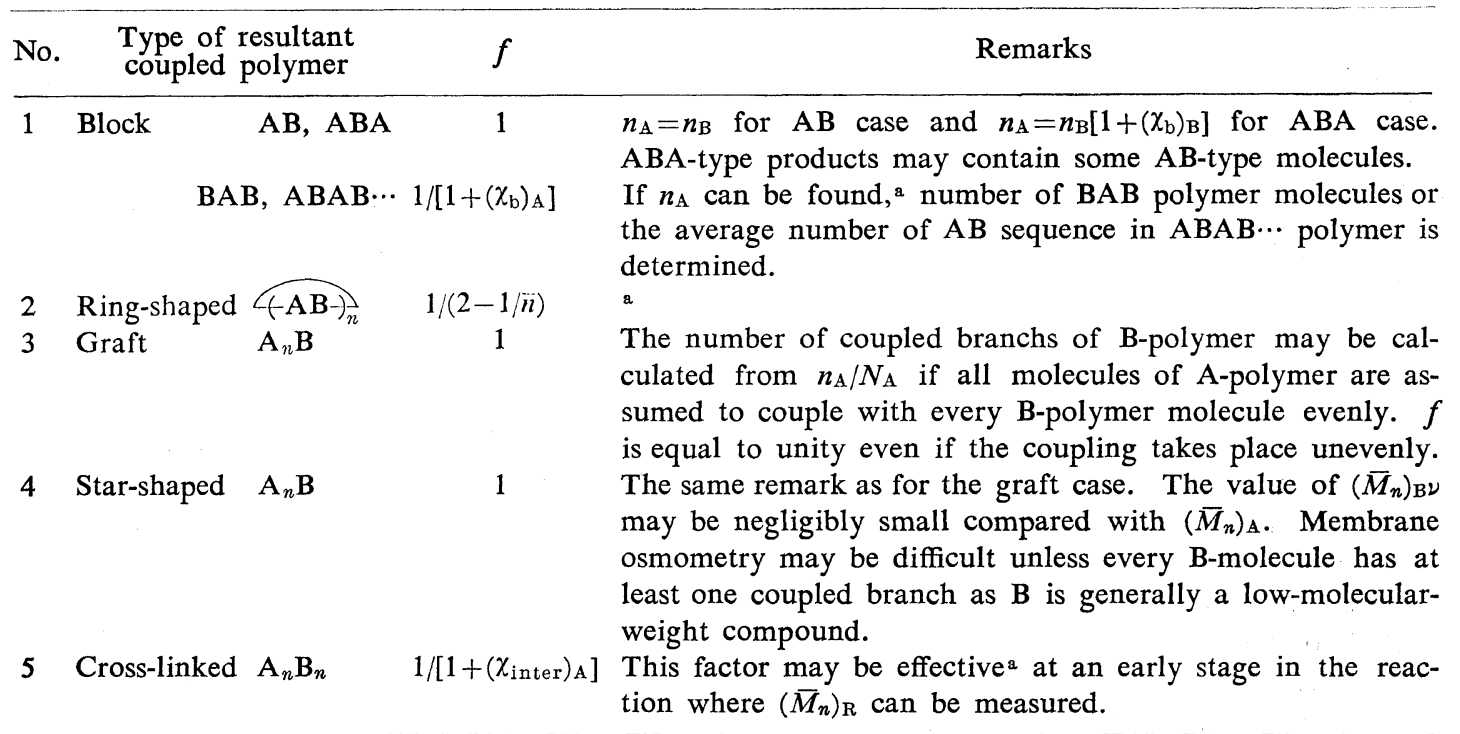

2 If $n_{\mathrm{A}} / N_{\mathrm{A}}$ can be guessed from model reactions or otherwise, $\left(\chi_{\mathrm{b}}\right)_{\mathrm{A}}, \bar{n},\left(\chi_{\text {inter }}\right)_{\mathrm{A}}$, or $\left(\chi_{\text {intra }}\right)\left(=1-\left(\chi_{\text {inter }}\right)_{\mathrm{A}}\right)$ can be estimated. 
Method for Evaluating the Extent of a Coupling Reaction

Table III. Application of eq 2 to the case of inert blends

\begin{tabular}{|c|c|c|c|c|c|}
\hline \multicolumn{6}{|c|}{ Inert blend } \\
\hline \multicolumn{2}{|c|}{ A-polymera } & & \multicolumn{3}{|c|}{ B-polymer ${ }^{b}$} \\
\hline $\mathrm{mg}$ & \multicolumn{2}{|l|}{$\mathrm{mol}^{\mathrm{e}}$} & $\mathrm{mg}$ & \multicolumn{2}{|c|}{$\operatorname{mol}^{\mathbf{f}}$} \\
\hline 9.5 & \multicolumn{2}{|c|}{$3.85 \times 10^{-7}$} & 80.4 & \multicolumn{2}{|c|}{$1.61 \times 10^{-7}$} \\
\hline 40.4 & \multicolumn{2}{|c|}{$1.64 \times 10^{-6}$} & 41.3 & \multicolumn{2}{|c|}{$8.29 \times 10^{-8}$} \\
\hline 79.8 & \multicolumn{2}{|c|}{$3.23 \times 10^{-6}$} & 10.2 & \multicolumn{2}{|c|}{$2.05 \times 10^{-8}$} \\
\hline \multirow{2}{*}{\multicolumn{6}{|c|}{$\begin{array}{l}\text { a Monodisperse polystyrene, }\left(\bar{M}_{n}\right)_{\mathrm{A}}=2.47 \times 10^{4} . \\
\text { b Monodisperse polystyrene, }\left(\bar{M}_{n}\right)_{\mathrm{B}}=49.8 \times 10^{4} \text {. } \\
\text { c Number-average molecular weight of the blend } \\
\text { a Calculated from the value of } 1+\nu-\left[\left(\bar{M}_{n}\right)_{\mathrm{A}}+(\bar{M}\right. \\
\text { negative small value is the experimental error } \\
\text { o, } \mathrm{O} \text { Obtained by dividing the weight of A- or } \\
N_{\mathrm{A}} / k \text { or } N_{\mathrm{B}} / k \text {, respectively, where } k \text { denotes A } \\
\text { g Determined by membrane osmometry. } \\
\text { h Calculated by the equation } n_{\mathrm{A}} / N_{\mathrm{A}}=1+\nu-\left[\left(\bar{M}_{n}\right)\right. \\
\text { Table IV. Comparison with other methodsa }\end{array}$}} \\
\hline & & & & & \\
\hline \multirow{2}{*}{ Method } & \multicolumn{5}{|c|}{ Extent of coupling of living PSt, $\%$} \\
\hline & \multicolumn{5}{|c|}{ Experiment no. } \\
\hline GPC & 58.7 & 33.1 & 76.5 & 59.7 & 77.7 \\
\hline $\begin{array}{l}\text { Turbidi- } \\
\text { metric } \\
\text { titration }\end{array}$ & 53 & 31 & - & - & - \\
\hline $\begin{array}{r}\text { Fractional } \\
\text { precipitat }\end{array}$ & on - & $\left\{\begin{array}{l}36.3^{\mathrm{b}} \\
18.0^{\mathrm{c}}\end{array}\right.$ & - & - & $78.7^{b}$ \\
\hline $\begin{array}{l}\text { This meth } \\
\text { (eq 2) }\end{array}$ & d 61.5 & 39.3 & 80.8 & 61.0 & 79.5 \\
\hline
\end{tabular}

a Procedure for the methods and the reaction conditions of coupling reactions are given in ref $2 \mathrm{a}$ for experiments SOL-1, SOL-5, SOL-23, and SOK-2 and in ref $2 \mathrm{~b}$ for $\mathrm{K}-3$.

b From the weight of fractionated graft polymer.

- From the number-average molecular weight of fractionated graft polymer.

investigation of the effect of various conditions on the reaction, as it may provide accuracy and facility in comparison with conventional methods which have been used until now such as (1) solvent extraction, ${ }^{3 \mathrm{a}}(2)$ fractional precipitation, ${ }^{3 \mathrm{~b}}$

(3) determination of the functional group remained, ${ }^{3 \mathrm{c}}$ (4) turbidimetric titration, ${ }^{3 \mathrm{~d}}$ or (5) gel permeation chromatography. ${ }^{3 \theta}$

The method was applied to the coupling reaction of living polystyrene with poly( $p$-vinylstyrene oxide $)^{2 \mathrm{a}}$ or poly(chloromethylstyrene) ${ }^{2 \mathrm{~b}}$ successfully, giving results in good agreement with other methods as shown in Table IV.

\section{REFERENCES}

1. For example, J. Pannell, Polymer, 12, 558 (1971); 13, 2 (1972).

2. For example, (a) M. Takaki, R. Asami, and M. Mizuno, Macromolecules, in press. (b) M. Takaki, R. Asami, and M. Ichikawa, ibid., in press.

3. For example, (a) S. P. Mitzengendler, G. A. Andreeva, K. J. Sokolova, and A. A. Korotkov, Vysokomol. Soedin., 4, 1366 (1962). (b) G. Finaz, Y. Gallot, J. Parrod, and P. Rempp, J. Polym. Sci., 58, 1363 (1962). (c) K. Ishizu, T. Fukutomi, and T. Kakurai, Polym. J., 7, 228 (1975). (d) Y. Minoura and H. Harada, J. Polym. Sci., Part A-1, 7, 3 (1969). (e) F. Candau and E. Franta, Makromol. Chem., 149, 41 (1971). 